\title{
Sleep duration and all-cause mortality in the elderly in China: a population-based cohort study
}

\author{
Yanfeng Ren', Maohua Miao², Wei Yuan² and Jiangwei Sun ${ }^{3^{*}}$ (D)
}

\begin{abstract}
Background: Although a U-shaped association between sleep duration and all-cause mortality has been found in general population, its association in the elderly adults, especially in the oldest-old, is rarely explored.

Methods: In present cohort study, we prospectively explore the association between sleep duration and all-cause mortality among 15,092 participants enrolled in the Chinese Longitudinal Healthy Longevity Survey (CLHLS) from 2005 to 2019. Sleep duration and death information was collected by using structured questionnaires. Cox regression model with sleep duration as a time-varying exposure was performed to calculate the hazard ratios (HRs) and 95\% confidence intervals (Cls). The dose-response association between them was explored via a restricted cubic spline function.
\end{abstract}

Results: During an average follow-up of 4.51 (standard deviation, SD: 3.62) years, 10,768 participants died during the follow-up period. The mean (SD) age of the participants was 89.26 (11.56) years old. Compared to individuals with moderate sleep duration (7-8 hours), individuals with long sleep duration (> 8 hours) had a significantly higher risk of all-cause mortality (HR: 1.13,95\%Cl: 1.09-1.18), but not among individuals with short sleep duration ( $\leq 6$ hours) (HR: 1.02, 95\%Cl: 0.96-1.09). Similar results were observed in subgroup analyses based on age and gender. In the dose-response analysis, a J-shaped association was observed.

Conclusions: Sleep duration was associated with all-cause mortality in a J-shaped pattern in the elderly population in China.

Keywords: Sleep duration, All-cause mortality, Elderly, Cohort

\section{Background}

As one of fundamental components of daily life, sleep is crucial for maintaining normal physiological function. According to the consensus of the National Sleep Foundation in the United States, the recommended level of sleep duration for young and older adults is 7-9 and 7-8 hours, respectively [1]. Inappropriate sleep duration, as reported by numerous studies, was associated with various adverse

\footnotetext{
* Correspondence: jiangwei.sun@ki.se

${ }^{3}$ Institute of Environmental Medicine, Karolinska Institutet, Stockholm, Sweden

Full list of author information is available at the end of the article
}

health outcomes including obesity, type 2 diabetes, cardiovascular disease, cancer, cognitive decline as well as total and cause-specific mortality [2-6]. A U-shaped pattern of the effects has been observed, that is long and short sleep duration increased the risk of all-cause mortality in general population $[7,8]$.

As aging is a big challenge faced by countries due to the advances in medical technology, improvements in lifestyle, and socioeconomic development, exploring how sleep duration is associated with all-cause mortality among the elderly population become more urgent. Compared with young adults, the elderly population are 
more likely to be affected by many factors, such as unhealthy lifestyles, menopausal status, chronic disease and mental health $[9,10]$, thus the relationship of sleep duration with all-cause mortality may be more complex. In addition, several issues have not been fully addressed in previous studies. First, the oldest-old population, such as octogenarians (person with $80-89$ years old), nonagenarians (person with 90-99 years old), or centenarians (person with more than 100 years old), was rarely enrolled, which makes a challenge to explore the effect of sleep duration on all-cause mortality among those specific population. Second, sleep duration was usually transformed to categorical variable in previous studies, thus the dose-response relationship between them have not been investigated in detail. Third, previous studies were more likely to only evaluate the effect of sleep duration that measured at baseline $[5,11]$, while failing to accounting for its variety after enrollment would translate into exposure misclassification and cause immoral time bias.

In present study, to fill the aforementioned knowledge gap, we used data from the Chinese Longitudinal Healthy Longevity Survey (CLHLS) to explore the relationship between sleep duration and all-cause mortality in the elderly adults, especially in the oldest-old.

\section{Methods}

\section{Study design}

We performed a cohort study by using data from the Chinese Longitudinal Healthy Longevity Survey (CLHL
S). A detailed information of CLHLS has been previously published [12]. Briefly, CLHLS, aimed to understand the factors influencing the health of the elderly adults (aged 65 years or above), especially the oldest-old (aged 80 years or above), is a nationwide survey conducted in 22 provinces in China, which covers about 85 percent of the total population [13]. A targeted and disproportionate sampling method was adopted to obtain a sample with enough sufficient number of the oldest-old. Eight waves were conducted in 1998, 2000, 2002, 2005, 2008 2009, 2011-2012, 2014 and 2018-2019, respectively, and sleep duration was initially measured from 2005 wave. Due to lacking of follow-up information, participants enrolled in 2018-2019 wave were excluded. A total of 19, 410 participants were initially enrolled in present study, and among them, 3,756 participants only having baseline information and 562 participants lacking information in sleep duration, birthday or end of follow up time, or younger than 65 years at baseline were further excluded from the analysis. Eventually, 15,092 participants were included. The flow chart of the participant selection was shown in Fig. 1.

\section{Sleep duration measurement and death assessment}

Sleep duration was assessed by the question "how long do you usually sleep". The participants or their close family members provided the information in the face to face interview. Participants were then categorized into 3 groups based on following criteria: short $(\leq 6 \mathrm{~h})$, moderate $(7-8 \mathrm{~h})$, or long $(>8 \mathrm{~h})$ sleep duration.

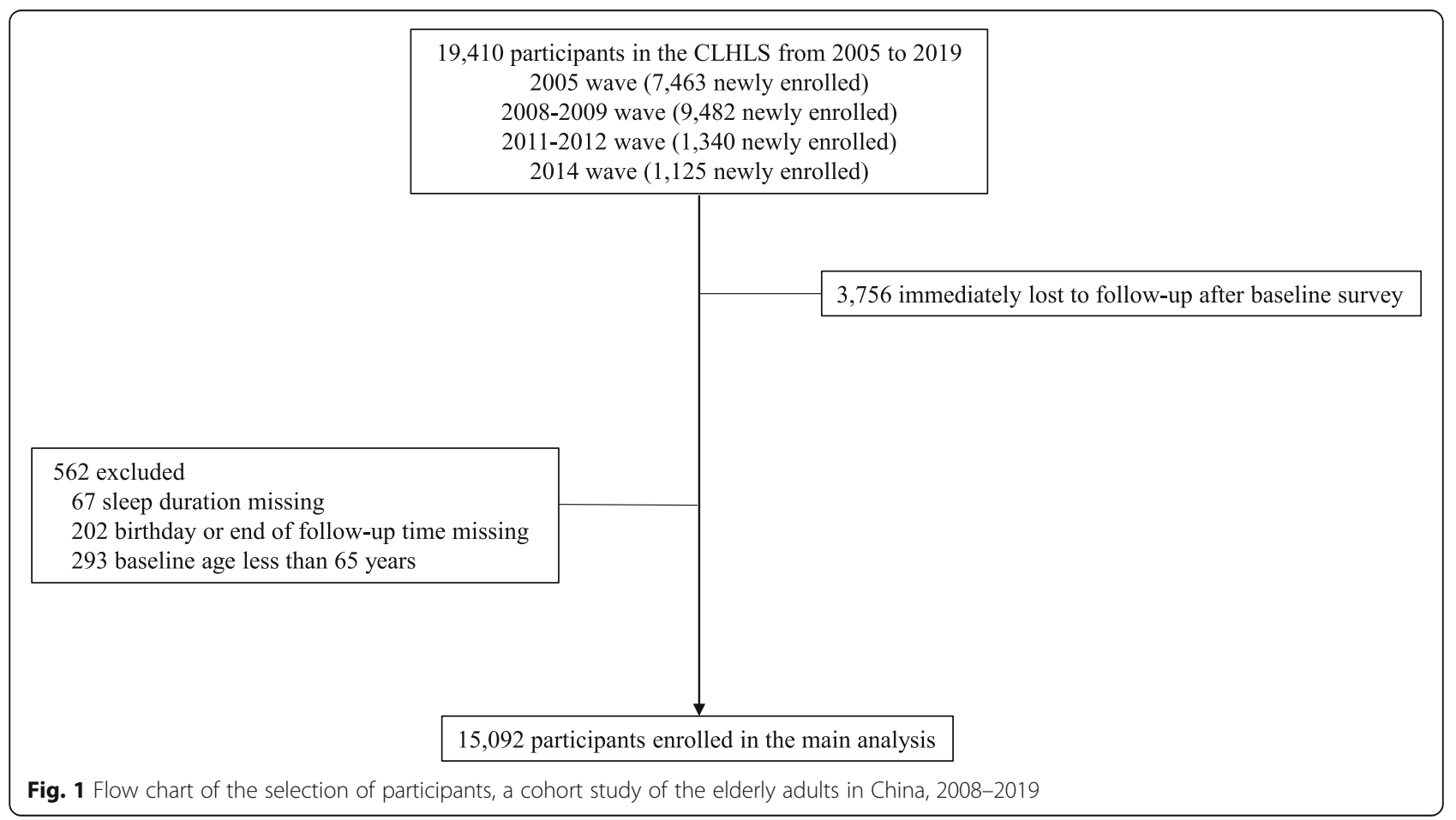


Date of death was confirmed via family member or the village doctor. Cause-specific mortality, however, was not considered in present study due to two main reasons: a). many of the elderly individuals die in a natural way at home rather than in hospital, thus cause of death were not recorded; b). cause of death that reported by family member were imprecise and unreliable [14]. All participants were followed from enrollment until death, lost to follow-up, or 31 July 2019, whichever came first.

\section{Covariates assessment}

To minimize the effect of potential confounders, sociodemographic information, lifestyle factors and health status of participant were adjusted. Socio-demographic information included age, sex (male/female), enrollment year (categorical variable: 2008, 2011, and 2014), province of residence (categorical), residence (city, town and rural area), ethic (Han/others), education (illiterate/primary school/middle school or above), marriage status (married/others), occupation (farmer or manual, clerical, professional, and others) and access to medical service (yes/no). Lifestyle factors included smoking (never, ever, and current smoker), drinking (never, ever, and current drinker), exercise (never, ever, and current exerciser), food diversity (measured by food diversity score), and social activity engagement (measured by social activity score). Health status information included activities in daily living (ADL, measured by ADL score), physical performance (measured by physical performance score), cognitive impairment (measured by Mini-Mental State Examination (MMSE) score) and chronic disease status (measured by chronic disease score). The definition of the abovementioned scores was described in one of our papers [15].

\section{Statistical analyses}

Cox regression models with baseline age as the underlying time scale were used to explore the association between sleep duration and all-cause mortality. As sleep duration could change after enrollment, we, therefore, modeled sleep duration as a time-varying exposure in Cox regression models to minimize the misclassification of exposure and immoral time bias [16]. A participant, for example, contributed person-years to moderate group if he/she had a sleep duration of 7 to 8 hours, while contributed to the long group from the date of being recorded with a long sleep duration $(>8 \mathrm{~h})$, until he/she was recorded with a different sleep status or he/ she reached one of the above mentioned follow-up end points.

A structured scheme of confounder adjustment was used to test the robustness of our findings. We first included age (underlying time scale) and sex as covariates in model 1. Then we adjusted for enrollment year, province of residence, residence, ethic, marriage status, occupation, access to medical service, smoking, drinking, and exercise in model 2. In model 3, we further adjusted for ADL score (categorical: 6, 5, 3-4, and 0-2), physical performance score (categorical: 5, 2.5-4.5, and 0-2.5), MMSE score (categorical: 24-30, 18-23, and 0-17), food diversity score (categorical: $6-8,4-5$, and $0-3$ ), social activity score (categorical: $5-8,3-4$, and $0-2$ ), and chronic disease score (categorical: $0,1-2$, and $\geq 3$ ). Subgroup analyses based on age and sex were performed, and whether heterogeneity existed within each subgroup were further explored by adding an interaction term of sleep status and either of the two factors in the Cox regression model. The proportional hazard assumption was evaluated via Schoenfeld residual plots and no violation was observed. Collinearity diagnostic was evaluated by the variance inflation factor and no collinearity among the covariates was found.

To assess the dose-response association between sleep duration and all-cause mortality, sleep duration was modeled via a restricted cubic spline function with knots selected at 25th, 50th, and 75th percentiles of its distribution in the model 3 . The reference value for sleep duration was chosen as 7 hours. We also explored whether the aforementioned knot selection was arbitrary by conducting sensitivity analyses using different knots selection, which was set at (6h, 7h, 8h), (5th, 50th, 95th ), (5th, 25th, 75th, 95th ), (5th, 25th, 50th, 75th, 95th ) of its distribution. We observed that compared to the results from the others, the result of selecting 25th, 50th, and 75th percentiles as knots was robust, as shown in Fig. 2.

Data analyses were performed using SAS version 9.4 (SAS Institute Inc, Cary, NC) and R platform. A twosided $P \leq 0.05$ was considered as statistically significant.

\section{Results}

\section{Characteristics of the study population}

During an average follow-up of 4.51 (standard deviation, SD: 3.62) years, 10,768 of the 15,092 participants died during the follow-up period. The mean (SD) age of the participants was 89.26 (11.56) years, ranging from 65 to 117 , and $40.5 \%$ were male.

Baseline characteristics stratified by categories of sleep duration are shown in Table 1. Compared to the subjects with moderate sleep duration, those with short or long sleep duration were more likely to be older, female, married, farmer or manual, illiterate, and live in rural area, but less likely to be current smokers, drinkers, and exercisers. The proportion of the subjects with lower ADL, physical performances, MMSE, food diversity, and social activity scores in moderate sleep duration group were lower than that in short and long sleep duration group. The proportion of the subjects with lower chronic disease scores and access to medical service 


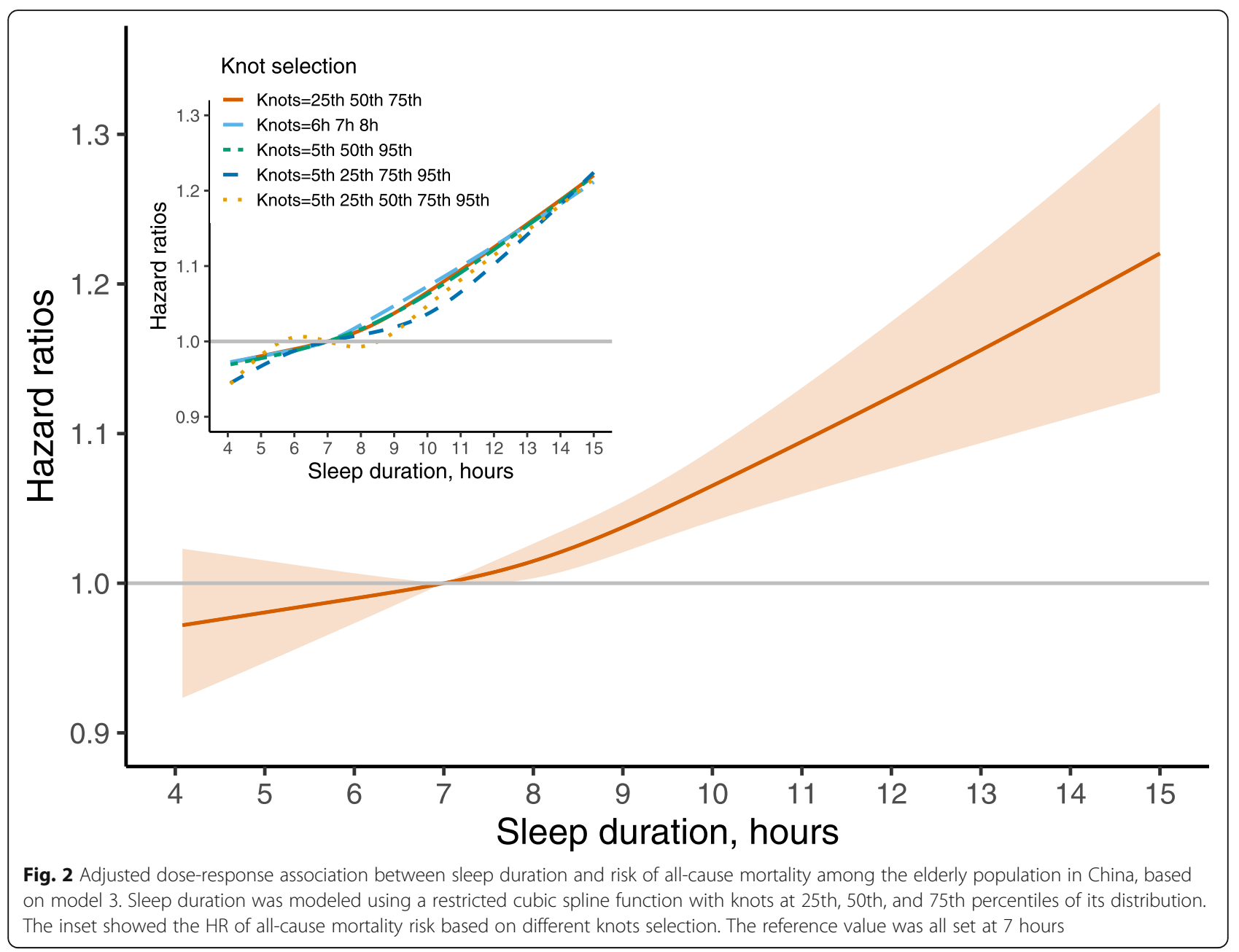

were lower in short sleep duration group but higher in long duration group. No significant difference was observed in ethic factor (Table 1).

\section{Risk of all-cause mortality with different sleep duration} In the whole population, consistent results were observed from model 1 , model 2 to model 3 (Table 2). Compared to the participants with moderate sleep duration, short sleep duration was insignificantly associated with increased all-cause mortality risk $(\mathrm{HR}=1.02,95 \%$ CI 0.96-1.09), however, long sleep duration was positively associated with risk of all-cause mortality $(\mathrm{HR}=$ 1.13, 1.09-1.18).

Similar pattern was observed in stratified analysis based on age and sex. The interaction effects of age, sex and sleep duration were both statistically significant $(P<$ $0.05)$. In age-stratified analysis, the risk of long sleep duration with all-cause mortality in the subgroup of less than 80 years $(\mathrm{HR}=1.20,1.02-1.41)$ was higher than that in other age groups [for 80-90 years: 0.95 (1.00$1.20)$; for $90-100$ years: $1.12(1.05-1.20)$; and for $>100$ years: $1.14(1.06-1.23)]$.

\section{The dose-response association between sleep duration and all-cause mortality}

In the dose-response analysis where 25th, 50th, and 75th percentiles of its distribution were selected as the knots, we observed a J-shaped pattern, however the non-linear test was not significant $\left(P_{\text {for non-linear test }}=0.1845\right)$. Similar patterns were also observed when other knot pets were used to construct the restricted cubic spline model (Fig. 2).

\section{Discussion}

In this prospective cohort study with the elderly participants aged 65 years and above, we found that long sleep duration was associated with an increased risk of allcause mortality and a J-shaped pattern between them was suggestive as well. The association was robust in subgroup analyses based on age and gender.

The relationship between sleep duration and all-cause mortality in the elderly has been previously explored, results however were inconsistent. Although most studies reported a U-shaped pattern, the age distribution of the enrolled population and the definition of sleep duration 
Table 1 Baseline characteristics of the elderly adults, a cohort study in China, 2005-2019

\begin{tabular}{|c|c|c|c|c|}
\hline \multirow[t]{2}{*}{ Variables } & \multicolumn{3}{|l|}{ Sleep duration } & \multirow[t]{2}{*}{$P$ value } \\
\hline & Short $(\leq 6 h), n=1,803$ & Moderate (7-8h), $n=7,459$ & Long $(>8 h), n=5,830$ & \\
\hline Age at baseline, years & & & & $<0.0001$ \\
\hline Mean \pm SD & $88.49 \pm 11.12$ & $87.07 \pm 12.08$ & $92.31 \pm 10.26$ & \\
\hline Categories, n(\%) & & & & $<0.0001$ \\
\hline$<80$ years & $381(21.13)$ & $1999(26.80)$ & $693(11.89)$ & \\
\hline $80-89$ years & $509(28.23)$ & $1888(25.31)$ & $1214(20.82)$ & \\
\hline 90-99 years & $522(28.95)$ & $2041(27.36)$ & $1939(33.26)$ & \\
\hline$\geq 100$ years & $391(21.69)$ & $1531(20.53)$ & $1984(34.03)$ & \\
\hline Sex, $n(\%)$ & & & & $<0.0001$ \\
\hline Male & $662(36.72)$ & $3198(42.87)$ & $2255(38.68)$ & \\
\hline Female & $1141(63.28)$ & $4261(57.13)$ & $3575(61.32)$ & \\
\hline Residence, n(\%) & & & & 0.0035 \\
\hline City & $328(18.19)$ & $1282(17.19)$ & $987(16.93)$ & \\
\hline Town & $297(16.47)$ & $1383(18.54)$ & $959(16.45)$ & \\
\hline Rural area & $1178(65.34)$ & $4794(64.27)$ & $3884(66.62)$ & \\
\hline Ethic, $n(\%)^{a}$ & & & & 0.0602 \\
\hline Han & $1696(95.71)$ & $6923(95.14)$ & $5367(95.82)$ & \\
\hline Others & $76(4.29)$ & $354(4.86)$ & $234(4.18)$ & \\
\hline Marriage status, $\mathrm{n}(\%)^{\mathrm{a}}$ & & & & $<0.0001$ \\
\hline Married & $1276(70.81)$ & $4898(65.78)$ & $4587(78.71)$ & \\
\hline Others & $526(29.19)$ & $2548(34.22)$ & $1241(21.29)$ & \\
\hline Occupation, $n(\%)^{a}$ & & & & $<0.0001$ \\
\hline Farmer or manual & $1451(80.97)$ & $5805(78.37)$ & $4775(82.41)$ & \\
\hline Clerical & $198(11.05)$ & $821(11.08)$ & $520(8.97)$ & \\
\hline Professional & $65(3.63)$ & $469(6.33)$ & $222(3.83)$ & \\
\hline Others & $78(4.35)$ & $312(4.21)$ & $277(4.78)$ & \\
\hline Education, $\mathrm{n}(\%)^{\mathrm{a}}$ & & & & $<0.0001$ \\
\hline Illiterate & $1253(70.31)$ & $4774(64.34)$ & $4140(71.40)$ & \\
\hline Primary school & $404(22.67)$ & $1929(26.00)$ & $1317(22.71)$ & \\
\hline Middle school or above & $125(7.01)$ & $717(9.66)$ & $341(5.88)$ & \\
\hline Access to medical service, $\mathrm{n}(\%)^{\mathrm{a}}$ & & & & 0.0059 \\
\hline Yes & $1531(84.91)$ & $6807(91.28)$ & $5412(92.86)$ & \\
\hline No & $272(15.09)$ & $650(8.72)$ & $416(7.14)$ & \\
\hline Smoking status, n(\%) ${ }^{\mathrm{a}}$ & & & & 0.0019 \\
\hline Never & $1279(70.98)$ & $5169(69.38)$ & $4116(70.70)$ & \\
\hline Ever smoker & $222(12.32)$ & $882(11.84)$ & $778(13.36)$ & \\
\hline Current smoker & $301(16.70)$ & 1399 (18.78) & $928(15.94)$ & \\
\hline Drinking status, $\mathrm{n}(\%)^{\mathrm{a}}$ & & & & 0.0019 \\
\hline Never & $1323(73.46)$ & $5373(72.18)$ & $4154(71.42)$ & \\
\hline Ever drinker & $188(10.44)$ & $659(8.85)$ & $606(10.42)$ & \\
\hline Current drinker & $290(16.10)$ & $1412(18.97)$ & $1056(18.16)$ & \\
\hline Exercise status, $n(\%)^{a}$ & & & & $<0.0001$ \\
\hline Never & $1216(67.52)$ & $5120(69.02)$ & $4148(71.36)$ & \\
\hline Ever exerciser & $182(10.11)$ & $421(5.68)$ & $461(7.93)$ & \\
\hline
\end{tabular}


Table 1 Baseline characteristics of the elderly adults, a cohort study in China, 2005-2019 (Continued)

\begin{tabular}{|c|c|c|c|c|}
\hline \multirow[t]{2}{*}{ Variables } & \multicolumn{3}{|l|}{ Sleep duration } & \multirow[t]{2}{*}{$P$ value } \\
\hline & Short $(\leq 6 h), n=1,803$ & Moderate (7-8h), $n=7,459$ & Long (> 8h), $n=5,830$ & \\
\hline Current exerciser & $403(22.38)$ & $1877(25.30)$ & $1204(20.71)$ & \\
\hline ADL score, $n(\%)^{a}$ & & & & $<0.0001$ \\
\hline 6 & $1350(75.33)$ & $6005(80.77)$ & $3838(66.01)$ & \\
\hline 5 & $143(7.98)$ & $587(7.90)$ & $752(12.93)$ & \\
\hline $3-4$ & $103(5.75)$ & $350(4.71)$ & $493(8.48)$ & \\
\hline $0-2$ & $196(10.94)$ & $493(6.63)$ & $731(12.57)$ & \\
\hline Physical performance score, $\mathrm{n}(\%)^{\mathrm{a}}$ & & & & $<0.0001$ \\
\hline 5 & $739(41.42)$ & $3831(51.67)$ & $2143(36.98)$ & \\
\hline $2.5-4.5$ & $797(44.67)$ & $2931(39.53)$ & $2787(48.09)$ & \\
\hline $0-2.5$ & $248(13.90)$ & $652(8.79)$ & $865(14.93)$ & \\
\hline MMSE score, $n(\%)^{a}$ & & & & $<0.0001$ \\
\hline $24-30$ & $764(46.59)$ & $3832(56.12)$ & $2078(39.65)$ & \\
\hline $18-23$ & $281(17.13)$ & $1146(16.78)$ & $968(18.47)$ & \\
\hline $0-17$ & $595(36.28)$ & $1850(27.09)$ & $2195(41.88)$ & \\
\hline Food diversity score, $\mathrm{n}(\%)^{\mathrm{a}}$ & & & & $<0.0001$ \\
\hline $6-8$ & $547(30.36)$ & $3036(40.77)$ & $2266(38.92)$ & \\
\hline $4-5$ & $618(34.30)$ & $2500(33.57)$ & $2149(36.91)$ & \\
\hline $0-3$ & $637(35.35)$ & $1911(25.66)$ & $1407(24.17)$ & \\
\hline Social activity score, $\mathrm{n}(\%)^{\mathrm{a}}$ & & & & $<0.0001$ \\
\hline $5-8$ & $111(6.16)$ & $766(10.27)$ & $287(4.92)$ & \\
\hline $3-4$ & $510(28.29)$ & $2602(34.90)$ & $1488(25.53)$ & \\
\hline $0-2$ & $1182(65.56)$ & $4088(54.83)$ & $4054(69.55)$ & \\
\hline Chronic disease score, $\mathrm{n}(\%)^{\mathrm{a}}$ & & & & $<0.0001$ \\
\hline 0 & $828(50.00)$ & $3932(57.38)$ & $3518(63.34)$ & \\
\hline $1-2$ & $664(40.10)$ & $2321(33.87)$ & $1633(29.40)$ & \\
\hline$\geq 3$ & $164(9.90)$ & $600(8.76)$ & $403(7.26)$ & \\
\hline
\end{tabular}

Abbreviations: $A D L$ activities of daily living, $I Q R$ interquartile range, MMSE Mini-Mental State Examination, $S D$ standard deviation

${ }^{\text {a }}$ Contains missing values. Ethic: 442, marriage status:16, occupation: 99 , access to medical service: 4, education:92, smoking status: 18 , drinking status: 31 ,

exercise status: 60 , ADL score: 51 , physical performance score: 99 , MMSE score: 1,383 , food diversity score: 21 , social activity score: 4 , chronic disease score: 1,029

$P$ values were derived from the ANOVA for continuous variables or the Chi-square test for categorical variables

were not identical $[5,17,18]$. In the First National Health and Nutrition Examination Survey with participants aged 60-86 years [17], compared to subjects with sleep duration of 7 hours, subjects with short ( $\leq 5$ hours) and long sleep duration ( $\geq 9$ hours) had an increased risk of mortality. In Singapore Chinese Health Study with participants aged 45-74 years, persistently short sleep ( $\leq 5$ hours) and long sleep ( $\geq 9$ hours) were associated with an increased risk of all-cause mortality as well when compared to the recommended sleep duration of 7 hours [18]. Åkerstedt et al. however only observed positive association among subjects less than 65 years, but not among subjects aged more than 65 years [11]. In contrast, Gangwisch et al. observed a U-shaped pattern among subjects from 60 to 86 years but not among those from 32 to 59 years [17].
Unlike the results from the previous studies [5, 17, 18], the present study suggested a J-shaped pattern between sleep duration and all-cause mortality. Our enrolled population (mean age: 89.26 years) were much older than that in the previous studies, which may partially explain the inconsistent findings, since the proportion of participants with short sleep duration tended to be decreasing with aging and the sample size in the group of short sleep duration thus tended to be smaller, which then may lead to insufficient statistical power. In addition, various definition of short sleep duration may be another explanation. For example, studies that using $\leq 5$ hours as the short sleep duration reported positive associations [5, 17], while one study that using less than 6 hours did not observed a positive association [19]. 
Table 2 Risk of all-cause mortality among the elderly adults with different sleep duration, a cohort study in China, 2005-2019

\begin{tabular}{|c|c|c|c|c|c|c|}
\hline \multirow[t]{2}{*}{ Population } & \multirow[t]{2}{*}{ Groups } & \multirow{2}{*}{$\begin{array}{l}\text { Cases/Person- } \\
\text { years }\end{array}$} & \multicolumn{3}{|l|}{$\mathrm{HR}(95 \% \mathrm{Cl})$} & \multirow{2}{*}{$\begin{array}{l}P \text { for } \\
\text { interaction }\end{array}$} \\
\hline & & & Model 1 & Model 2 & Model 3 & \\
\hline \multirow[t]{3}{*}{ Whole population } & Short ( $\leq 6 h)$ & $1340 / 9518$ & $1.08(1.01-1.14)$ & $1.07(1.00-1.13)$ & $1.02(0.96-1.09)$ & \\
\hline & Moderate (7-8h) & $4578 / 35942$ & Ref. & Ref. & Ref. & \\
\hline & Long (> 8h) & $4806 / 22567$ & $1.20(1.15-1.25)$ & $1.17(1.12-1.22)$ & $1.13(1.09-1.18)$ & \\
\hline \multirow[t]{3}{*}{ Male } & Short ( $\leq 6 h)$ & $485 / 3642$ & $1.13(1.02-1.25)$ & $1.09(0.99-1.21)$ & $1.02(0.92-1.13)$ & \\
\hline & Moderate (7-8h) & $1867 / 16294$ & Ref. & Ref. & Ref. & 0.0300 \\
\hline & Long (> 8h) & $1755 / 9759$ & $1.14(1.07-1.22)$ & $1.11(1.04-1.19)$ & $1.08(1.01-1.15)$ & \\
\hline \multirow[t]{3}{*}{ Female } & Short ( $\leq 6 h)$ & $855 / 5876$ & $1.05(0.97-1.14)$ & $1.06(0.98-1.14)$ & $1.02(0.94-1.10)$ & \\
\hline & Moderate (7-8h) & $2711 / 19648$ & Ref. & Ref. & Ref. & \\
\hline & Long (> 8h) & $3051 / 12808$ & $1.24(1.18-1.31)$ & $1.20(1.14-1.26)$ & $1.17(1.11-1.23)$ & \\
\hline \multirow[t]{3}{*}{ Age at baseline, $<80$ years } & Short $(\leq 6 h)$ & $132 / 3774$ & $1.13(0.93-1.37)$ & $1.07(0.88-1.30)$ & $1.04(0.85-1.26)$ & \\
\hline & Moderate (7-8h) & $452 / 15585$ & Ref. & Ref. & Ref. & 0.0034 \\
\hline & Long (> 8h) & $221 / 5518$ & $1.29(1.10-1.52)$ & $1.25(1.06-1.47)$ & $1.20(1.02-1.41)$ & \\
\hline \multirow[t]{3}{*}{ Age at baseline, 80-89 years } & Short $(\leq 6 h)$ & $371 / 2867$ & $1.02(0.90-1.14)$ & $1.01(0.90-1.13)$ & $0.95(0.85-1.07)$ & \\
\hline & Moderate (7-8h) & $1155 / 9203$ & Ref. & Ref. & Ref. & \\
\hline & Long (> 8h) & $949 / 6020$ & $1.17(1.07-1.28)$ & $1.12(1.03-1.23)$ & $1.10(1.00-1.20)$ & \\
\hline \multirow[t]{3}{*}{ Age at baseline, $90-99$ years } & Short $(\leq 6 h)$ & $458 / 1827$ & $1.11(1.00-1.23)$ & $1.10(0.99-1.22)$ & $1.04(0.94-1.16)$ & \\
\hline & Moderate (7-8h) & $1631 / 7085$ & Ref. & Ref. & Ref. & \\
\hline & Long (> 8h) & $1775 / 6265$ & $1.21(1.13-1.30)$ & $1.17(1.10-1.26)$ & $1.12(1.05-1.20)$ & \\
\hline \multirow[t]{3}{*}{ Age at baseline, $\geq 100$ years } & Short $(\leq 6 h)$ & $379 / 1049$ & $1.10(0.98-1.23)$ & $1.11(0.98-1.24)$ & $1.06(0.95-1.20)$ & \\
\hline & Moderate (7-8h) & $1340 / 4069$ & Ref. & Ref. & Ref. & \\
\hline & Long (> 8h) & $1861 / 4763$ & $1.19(1.11-1.28)$ & $1.16(1.08-1.25)$ & $1.14(1.06-1.23)$ & \\
\hline
\end{tabular}

Model 1: adjusted for age and sex; Model 2: adjusted for age, sex, enrollment year, province, residence, education, ethic, marriage status, occupation, access to medical service, smoking status, drinking status, and exercise status; Model 3: model $2+$ further adjusted for ADL score, physical performance score, MMSE score, food diversity score, social activity score, and chronic disease score.

Abbreviations: Cls confident intervals, HR hazard ratio

In the stratified analysis by age, J-shaped pattern was consistently observed across four age groups. In previous studies [5, 17], 60 or 65 years was usually used as the cut-points because the enrolled participants were relatively younger. Consistent with the findings among the younger elderly [5, 17], our present study also found long sleep duration was associated with an increased risk of all-cause mortality among the oldest-old adults, which provided new evidence for the influence of sleep duration on those rarely investigated population. Moreover, the risk of all-cause mortality was higher in subjects aged less than 80 years than that among other age groups, which might be partially explained by survival bias: the longer the elderly live, the healthier they might be. For example, in present study, the prevalence of chronic disease was decreasing with aging, which was $50.29,45.57,37.07$ and $34.75 \%$ in the group aged less than 80 years, $89-90$ years, $90-100$ years, and over 100 years, respectively.

The associations of sleep duration with all-cause mortality across gender have been inconsistent as well. In the Korean Multi-center Cancer Cohort Study, the U- shape relationship was only seen in female [5], while in Hublin et al. study, same relationship was only observed in male [7]. However, in a study with community-living adults aged more than 65 years, long sleep duration ( $\geq 10$ hours) was associated with higher risk of mortality in both female and male [20]. Similar to our result, one population-based cohort study from China observed a J-shaped association of sleep duration with all-cause mortality risk both in male aged $40-75$ years and female aged 44-79 years [19].

Although the mechanisms for the relationship between sleep duration and all-cause mortality risk remain unclear, several possible explanations have been proposed: (a) sleep fragmentation and snoring linked to long sleep duration were independent risk factor for cardio- and cerebro-vascular diseases $[21,22]$, which are the leading causes of mortality worldwide; (b) long sleep duration may lead to lethargy and fatigue, decrease the resistance to stress and disease, and then increase the consequent mortality risk [23]; (c) long sleep duration demonstrated strong associations with chronic diseases including cognitive impairment, depression, mental distress, stroke, 
coronary heart disease, and diabetes [6, 24-26], which may mediate the relationship between long sleep duration and mortality, although health conditions were adjusted for in present and previous studies; (d) photoperiod reduction arising from long sleep duration may increase the risk of mortality directly [27]. Similar to long sleep duration, the influence of short sleep duration on mortality may be mediated by some disorders or diseases, such as obesity, cancer, infectious and chronic diseases [24, 28, 29].

Strengths of our study include the prospective cohort study design, long follow-up time, and a large sample size. In addition, taking into account the change of sleep duration in the follow-up enabled us to more precisely evaluate the association, which may eliminate the misclassification of exposure status to a large extent. Moreover, the studied population was mainly consisted of oldest-old adults, such as octogenarians, nonagenarians, and centenarians, for whom the influence of sleep duration on all-cause mortality was rarely explored.

This study also has several limitations. Firstly, sleep duration, like many previous studies, was collected through self-report, which might lead to misclassification of exposure. However, studies suggested that selfreported sleep duration was well-correlated with sleep duration objectively measured by actigraphy- and singlenight in-home polysomnography [30, 31]. Secondly, although a wide range of lifestyle factors and health conditions (i.e., cognitive impairment, social activity engagement, chronic disease status) were adjusted for in our study, the influence of residual confounding, caused by measured or unmeasured confounders (e.g., the severity of chronic diseases), cannot be ruled out. However, the consistent results from main analyses to subgroup analyses argue against that residual confounding would overturn our results in this case. Thirdly, the study population represented the elderly individuals in China, therefore the generalization of present findings to other age groups, areas or ethnicities should be done with caution.

\section{Conclusions}

In summary, we found that long sleep duration was associated with a higher risk of all-cause mortality among the elderly population. Given sleep duration can be easily measured in practice, it should be regarded as a useful signal to alert healthcare providers, family members, and the elderly population for the risk of mortality.

\section{Abbreviations}

CLHLS: Chinese Longitudinal Healthy Longevity Survey; HRs: Hazard ratios; Cls: Confidence intervals; SD: Standard deviation; ADL: Activities in daily living; MMSE: Mini-Mental State Examination

\section{Acknowledgements}

We thank all investigators and participants who conducting and participating in the Chinese Longitudinal Healthy Longevity Survey.

\section{Authors' contributions}

JS designed the study and analyzed the results; YR and JS drafted the paper. YR, JS MM and WY have contributed to the interpretation of findings and provided revisions to the manuscript. All authors have read and approved the final manuscript.

\section{Funding}

This work is supported by grants from Shandong Medical and Health Science and Technology Development Project [grant numbers 2018WS060] and the Chinese Scholarship Council. The funder had no role in study design, data collection and analysis, decision to publish, or preparation of the manuscript. Open Access funding provided by Karolinska Institute.

\section{Availability of data and materials}

All data used in this study was stored at Peking university (http://opendata. pku.edu.cn/), researchers can contact qwang@nsd.pku.edu.cn to apply for the data.

Ethics approval and consent to participate

Research Ethics Committees of Peking University approved the CLHLS, and written informed consents from all participants or their representatives were collected.

\section{Consent for publication}

Not applicable.

\section{Competing interests}

The authors declare that they have no competing interests.

\section{Author details}

'Department of Health Statistics, School of Public Health, Weifang Medical University, Shandong, China. ${ }^{2} \mathrm{NHC}$ Key Lab. of Reproduction Regulation, Shanghai Institute of Planned Parenthood Research), Fudan University, Shanghai, China. ${ }^{3}$ Institute of Environmental Medicine, Karolinska Institutet, Stockholm, Sweden.

Received: 21 September 2020 Accepted: 14 December 2020

Published online: 30 December 2020

\section{References}

1. Hirshkowitz M, Whiton K, Albert SM, Alessi C, Bruni O, DonCarlos L, Hazen N, Herman J, Adams Hillard PJ, Katz ES, et al. National Sleep Foundation's updated sleep duration recommendations: final report. Sleep Health. 2015; 1(4):233-43.

2. Kripke DF, Langer RD, Elliott JA, Klauber MR, Rex KM. Mortality related to actigraphic long and short sleep. Sleep Med. 2011;12(1):28-33.

3. Buxton OM, Marcelli E. Short and long sleep are positively associated with obesity, diabetes, hypertension, and cardiovascular disease among adults in the United States. Soc Sci Med. 2010;71(5):1027-36.

4. Stone CR, Haig TR, Fiest KM, McNeil J, Brenner DR, Friedenreich CM. The association between sleep duration and cancer-specific mortality: a systematic review and meta-analysis. Cancer Causes Control. 2019;30(5): 501-25.

5. Yeo Y, Ma SH, Park SK, Chang SH, Shin HR, Kang D, Yoo KY. A prospective cohort study on the relationship of sleep duration with all-cause and disease-specific mortality in the Korean Multi-center Cancer Cohort study. J Prev Med Public Health. 2013;46(5):271-81.

6. Chen JC, Espeland MA, Brunner RL, Lovato LC, Wallace RB, Leng X, Phillips LS, Robinson JG, Kotchen JM, Johnson KC, et al. Sleep duration, cognitive decline, and dementia risk in older women. Alzheimers Dement. 2016;12(1): 21-33.

7. Hublin C, Partinen M, Koskenvuo M, Kaprio J. Sleep and mortality: a population-based 22-year follow-up study. Sleep. 2007;30(10):1245-53.

8. Zawisza K, Tobiasz-Adamczyk B, Galas A, Brzyska M. Sleep duration and mortality among older adults in a 22-year follow-up study: an analysis of possible effect modifiers. Eur J Ageing. 2015;12(2):119-29. 
9. Tamakoshi A, Ohno Y. Self-reported sleep duration as a predictor of allcause mortality: results from the JACC study, Japan. Sleep. 2004;27(1):51-4.

10. Gulia KK, Kumar VM. Sleep disorders in the elderly: a growing challenge. Psychogeriatrics. 2018;18(3):155-65.

11. Åkerstedt T, Ghilotti F, Grotta A, Bellavia A, Lagerros YT, Bellocco R. Sleep duration, mortality and the influence of age. Eur J Epidemiol. 2017;32(10): 881-91.

12. Zheng Z. Twenty years' follow-up on elder people's health and quality of life. China Popul Dev Stud. 2020;3:297-309.

13. Zeng Y, Feng Q, Hesketh T, Christensen K, Vaupel JW. Survival, disabilities in activities of daily living, and physical and cognitive functioning among the oldest-old in China: a cohort study. The Lancet. 2017;389(10079):1619-29.

14. Zeng Y. Towards Deeper Research and Better Policy for Healthy Aging --Using the Unique Data of Chinese Longitudinal Healthy Longevity Survey. China Economic J. 2012:5(2-3):131-49.

15. Sun J, Li L, Sun JW: Sensory impairment and all-cause mortality among the elderly adults in China: A population-based cohort study. Aging 2020;12(23): 24288-300.

16. Levesque LE, Hanley JA, Kezouh A, Suissa S. Problem of immortal time bias in cohort studies: example using statins for preventing progression of diabetes. Bmj. 2010;340:b5087.

17. Gangwisch JE, Heymsfield SB, Boden-Albala B, Buijs RM, Kreier F, Opler MG, Pickering TG, Rundle AG, Zammit GK, Malaspina D. Sleep duration associated with mortality in elderly, but not middle-aged, adults in a large US sample. Sleep. 2008;31(8):1087-96.

18. Soh AZ, Chee MWL, Yuan JM, Koh WP. Sleep lengthening in late adulthood signals increased risk of mortality. Sleep. 2018;41(3):zsy005.

19. Cai H, Shu XO, Xiang YB, Yang G, Li H, Ji BT, Gao J, Gao YT, Zheng W. Sleep duration and mortality: a prospective study of 113138 middle-aged and elderly Chinese men and women. Sleep. 2015;38(4):529-36.

20. Lee JS, Auyeung TW, Leung J, Chan D, Kwok T, Woo J, Wing YK. Long sleep duration is associated with higher mortality in older people independent of frailty: a 5-year cohort study. J Am Med Dir Assoc. 2014;15(9):649-54.

21. Li Y, Sato Y, Yamaguchi N. Lifestyle factors as predictors of general cardiovascular disease: use for early self-screening. Asia Pac J Public Health. 2014;26(4):414-24.

22. Wolkove N, Elkholy O, Baltzan M, Palayew M. Sleep and aging: 1. Sleep disorders commonly found in older people. CMAJ. 2007;176(9):1299-304.

23. Grandner MA, Drummond SP. Who are the long sleepers? Towards an understanding of the mortality relationship. Sleep Med Rev. 2007;11(5):341-60.

24. Liu Y, Wheaton AG, Chapman DP, Croft JB. Sleep duration and chronic diseases among U.S. adults age 45 years and older: evidence from the 2010 Behavioral Risk Factor Surveillance System. Sleep. 2013;36(10):1421-7.

25. Patel SR, Malhotra A, Gottlieb DJ, White DP, Hu FB. Correlates of long sleep duration. Sleep. 2006;29(7):881-9.

26. Nicholson K, Rodrigues R, Anderson KK, Wilk P, Guaiana G, Stranges S. Sleep behaviours and multimorbidity occurrence in middle-aged and older adults: findings from the Canadian Longitudinal Study on Aging (CLSA). Sleep Med. 2020;75:156-62

27. Aujard F, Dkhissi-Benyahya O, Fournier I, Claustrat B, Schilling A, Cooper HM, Perret M. Artificially accelerated aging by shortened photoperiod alters early gene expression (Fos) in the suprachiasmatic nucleus and sulfatoxymelatonin excretion in a small primate, Microcebus murinus. Neuroscience. 2001;105(2):403-12.

28. Parish JM. Sleep-related problems in common medical conditions. Chest. 2009;135(2):563-72.

29. Cappuccio FP, Cooper D, D'Elia L, Strazzullo P, Miller MA. Sleep duration predicts cardiovascular outcomes: a systematic review and meta-analysis of prospective studies. Eur Heart J. 2011;32(12):1484-92.

30. Jackson CL, Patel SR, Jackson WB 2nd, Lutsey PL, Redline S. Agreement between self-reported and objectively measured sleep duration among white, black, Hispanic, and Chinese adults in the United States: Multi-Ethnic Study of Atherosclerosis. Sleep. 2018;41(6):zsy057.

31. Lockley SW, Skene DJ, Arendt J. Comparison between subjective and actigraphic measurement of sleep and sleep rhythms. J Sleep Res. 1999;8(3):175-83.

\section{Publisher's Note}

Springer Nature remains neutral with regard to jurisdictional claims in published maps and institutional affiliations.

\section{Ready to submit your research? Choose BMC and benefit from:}

- fast, convenient online submission

- thorough peer review by experienced researchers in your field

- rapid publication on acceptance

- support for research data, including large and complex data types

- gold Open Access which fosters wider collaboration and increased citations

- maximum visibility for your research: over $100 \mathrm{M}$ website views per year

At BMC, research is always in progress.

Learn more biomedcentral.com/submissions 